\title{
George de Hevesy in America
}

TO THE EDITOR: George de Hevesy was a Hungarian radiochemist who was awarded the Nobel Prize in Chemistry in 1943 for the discovery of the radiotracer principle (1). As the radiotracer principle is the foundation of all diagnostic and therapeutic nuclear medicine procedures, Hevesy is widely considered the father of nuclear medicine (1). Although it is well-known that he spent time at several European institutions, it is not widely known that he also spent $6 \mathrm{wk}$ at Cornell University in Ithaca, New York, in the fall of 1930 as that year's Baker Lecturer in the Department of Chemistry (2-6). "[T]he Baker Lecturer gave 2 formal presentations per week, to a large and diverse audience and provided an informal seminar weekly for students and faculty members interested in the subject. The lecturer had an office in Baker Laboratory and was available to faculty and students for further discussion" (7). There is also evidence that, "... Hevesy visited Harvard [University, Cambridge, MA] as a Baker Lecturer at Cornell in 1930..." (8).

Neither of the authors of this Letter to the Editor was aware of Hevesy's association with Cornell University despite our longstanding ties to Cornell until one of us (William. C. Klingensmith) noticed the association in Hevesy's biographic page on the official Nobel website (6). Klingensmith obtained both his undergraduate degree and his medical degree from Cornell in Ithaca and New York City, respectively, and spent his career in nuclear medicine. Joseph R. Osborne did his nuclear medicine training at Columbia University and has subsequently been a faculty member of Weill Cornell Medical College for the last $11 \mathrm{y}$ (with a brief tenure at Memorial Sloan Kettering Cancer Center [affiliated with Cornell]) and is now the program director of the Nuclear Medicine residency and Chief of the Molecular Imaging and Therapeutics Section.

George de Hevesy spent time at an unusually large number of European universities. This fact is sometimes attributed to his family wealth, which allowed him to choose his research environment, but the Nazi takeover of Germany and adjacent countries was also a factor. Here is a brief chronologic list of universities that Hevesy was associated with including selected details: Piarista Catholic Grammar School (graduated in 1903, age 17, specialized in mathematics and physics); University of Budapest (1 y of college); Berlin's Technical University (to study chemical engineering; contracted pneumonia and was advised to move to a university with a warmer climate); University of Freiburg (completed his doctorate degree in 1908); Technical University of Zurich, Switzerland (postdoctoral assistant; Albert Einstein arrived a year later); Karlsruhe, Germany, (worked with famous chemist Fritz Haber); University of Manchester, Manchester, England (1911, worked with Ernest Rutherford; discovered radiotracer principle at age 27, which led to a Nobel Prize); University of Budapest (1918, professor of physical chemistry); University of Copenhagen (1920, worked with Niels Bohr; began study of biologic systems with radiotracers; co-discoverer of element 72, Hafnium [Hafnia is Latin for Copenhagen]); University of Freiburg (1926, professor of physical chemistry); Cor-

COPYRIGHT @ 2020 by the Society of Nuclear Medicine and Molecular Imaging. nell University (1930, Baker Lecturer); University of Freiburg (Hevesy loved the city of Freiburg); University of Copenhagen (1934, back to Copenhagen because of Nazi takeover in Germany); Institute of Research in Organic Chemistry, Stockholm, Sweden (1944, became dangerous to remain in Copenhagen because of the Nazis; being a Nobel Laureate allowed him to become a Swedish citizen); and University of Stockholm (in his retirement, he remained an active scientific associate of the University of Stockholm) (1). Hevesy was associated with 8 European universities, several more than once, and 1 American university, Cornell University.

One reason that Hevesy's association with Cornell may be easily overlooked is that he is not included in the list of 50 Nobel Prize winners associated with Cornell University $(9,10)$. A detailed general analysis of Nobel Laureates associated with universities can be found on Wikipedia (11). The analysis states that, "The official academic affiliations fall into 3 categories: 1) Alumni (graduate \& attendee), 2) Long-term academic staff, and 3) Short-term academic staff." Short-term academic staff is defined as, "all employment-based visiting positions, which carry teaching/research duties, are included as affiliations in the list." Cornell requires that the individual conduct research at the University, not just teaching (Brian Crane, written communication, June 2019). Of interest, since its inception in 1927, 26 of the 99 Baker Lecturers (26\%) have won a Nobel Prize.

In 1958 Hevesy became an honorary member of the U.S.-based Society of Nuclear Medicine and Molecular Imaging (formerly Society of Nuclear Medicine). In 1960, the Society of Nuclear Medicine initiated the George Charles de Hevesy Nuclear Pioneer Award in conjunction with the Hevesy Nuclear Medicine Pioneer Lecture; this is the most prestigious award given by the Society of Nuclear Medicine and Molecular Imaging (12).

\section{REFERENCES}

1. Niese S. The Nobel Laureate George de Hevesy (1885-1966)—universal genius and father of nuclear medicine. Scholarena website. http://article.scholarena.com/ The-Nobel-Laureate-George-de-Hevesy-1885-1966-Universal-Genius-and-Fatherof-Nuclear-Medicine.pdf. Accessed November 21, 2019.

2. George de Hevesy: famous scientists, the art of genius. Famousscientists website. https://www.famousscientists.org/george-de-hevesy/. Accessed November 21, 2019.

3. George de Hevesy. Wikipedia website. https://en.wikipedia.org/wiki/George_de_Hevesy. Accessed November 21, 2019.

4. Georg von Hevesy: important dates: 1930-1934 Baker lecturer, Cornell University, Ithaca, NY. American Institute of Physics website. https://history.aip.org/phn/ 11711004.html. Accessed November 21, 2019.

5. Previous Baker lecturers, fall 1930. Department of Chemistry \& Chemical Biology. The department of chemistry and chemical biology, previous Baker lecturers, Cornell University website. https://chemistry.cornell.edu/previous-baker-lectures. Accessed November 21, 2019. 
6. de Hevesy G. Biographical: the Nobel prize. Nobel Prize website. https://www. nobelprize.org/prizes/chemistry/1943/hevesy/biographical/. Accessed November 21, 2019.

7. Cornell University. Named lecture series: Baker lectures. The department of chemistry and chemical biology, colloquia, Cornell University website. https:// chemistry.cornell.edu/colloquia. Accessed November 21, 2019.

8. De Hevesy George, 1885-1966, elected for membership, Royal Society 1939:125166. Royal Society website. https://royalsocietypublishing.org/doi/pdf/10.1098/ rsbm.1967.0007. Accessed November 21, 2019.

9. Nobel Laureates affiliated with Cornell University (50 laureates). News, Cornell University website. http://news.cornell.edu/content/nobel-laureates-affiliated-cornelluniversity. Accessed November 21, 2019.

10. 50 universities with the most Nobel Prize winners. Best Masters programs website. https://www.bestmastersprograms.org/50-universities-with-the-most-nobelprize-winners/. Accessed November 21, 2019.

11. List of Nobel laureates by university affiliation, Cornell University (12th), Note: 1) The University Count of Cornell does not include short-term academic staff (Fritz Lipmann being an exception). https://en.wikipedia.org/wiki/List_of_ Nobel_laureates_by_university_affiliation. Accessed: November 21, 2019.

12. Georg Charles de Hevesy Nuclear Pioneer Awardees. Society of Nuclear Medicine and Molecular Imaging website. http://snmmi.files.cms-plus.com/docs/Grants_and_ Awards/deHevesyAwardeeList.pdf. Accessed November 21, 2019.

\section{William C. Klingensmith III* Joseph R. Osborne *Weill Cornell Medicine \\ 520 East $70^{\text {th }}$ St., New York, NY 10021 E-mail: nid2697@nyp.org}

Published online Jul. 13, 2019.

DOI: 10.2967/jnumed.119.233254

\section{ABCG2- and ABCB1 Inhibition Using Supratherapeutic Doses of Erlotinib: Clinical Implications in the Treatment of Central Nervous System Metastases}

TO THE EDITOR: We read with great interest the article by Bauer et al. titled "A Proof-of-Concept Study to Inhibit ABCG2and ABCB1-Mediated Efflux Transport at the Human Blood-Brain Barrier." They concluded that ABCB1 inhibition by tariquidar (an $\mathrm{ABCB} 1$ inhibitor) was not able to enhance ${ }^{11} \mathrm{C}$-erlotinib brain uptake, but supratherapeutic doses of erlotinib (a dual ABCB1/ABCG2 substrate) before PET scanning could increase ${ }^{11} \mathrm{C}$-erlotinib brain uptake significantly, when $650 \mathrm{mg}$ or more of erlotinib were administered (1). Previous research from our group using elacridar (also an $\mathrm{ABCB} 1$ inhibitor) and ${ }^{11} \mathrm{C}$-erlotinib PET showed that elacridar was ineffective in blocking ABCG2 (2). The present study underlines the major barrier role of ABCG2, as it showed that ABCG2 was also insufficiently targeted by tariquidar to achieve significant inhibition of this efflux pump.

Tyrosine kinase inhibitors (TKIs) directed against epidermal growth factor receptor (EGFR), including erlotinib and osimertinib, are all substrates for $\mathrm{ABCB} 1$ and $\mathrm{ABCG} 2$ transporters. For erlotinib, we showed that ${ }^{11} \mathrm{C}$-erlotinib uptake decreased on treatment with erlotinib (150 mg daily) in tumors, but also in liver tissue, due to EGFR saturation and lowering of the specific binding of ${ }^{11} \mathrm{C}$-erlotinib to the EGFR target $(3,4)$. However, Bauer et al. showed that supratherapeutic doses of erlotinib led to an increase in the brain uptake, probably through saturation of the ABCB1/ABCG2 efflux pumps leading to elevated nonspecific uptake of ${ }^{11} \mathrm{C}$-erlotinib in the brain as no relevant target EGFR expression is expected in brain tissue.
There is a therapeutic interest in understanding how these efflux pumps can be influenced. Inhibiting erlotinib efflux could benefit EGFR mutation-positive non-small cell lung cancer (NSCLC) patients with metastases of the central nervous system, which are among the most difficult to treat. Especially, leptomeningeal metastases are often refractory to standard dose therapy as a result of lowered anticancer drug concentration in the cerebrospinal fluid. One strategy to achieve control is to use supratherapeutic doses of erlotinib, where doses of $1,500 \mathrm{mg}$ (10 times the standard daily dose of $150 \mathrm{mg} / \mathrm{d}$ ) once per week were shown to be effective (5). Although this regimen is successful in certain cases, it is restricted by higher toxicity. The Bauer et al. study showed a $27 \%$ increase of VT (volume of distribution) and a $94 \%$ increase of AUC (area under the curve) at 1,000 mg, implying a significant clinical benefit. However, they also encountered an increase of adverse events in this group up to the point where inclusion was discontinued. Results using a lower dose, that is, $650 \mathrm{mg}$, showed a similar increase in VT (23\%) and still a significant increase in AUC (78\%). This implies that this dose could be sufficient to overcome active efflux of erlotinib with less toxicity. This insight could open the door to different scheduling and dosing regimens.

The treatment landscape for EGFR mutation-positive NSCLC is also evolving. The FLAURA trial showed that osimertinib, a third-generation EGFR-TKI, was more effective than first-generation EGFR-TKIs such as erlotinib for both progression free-survival and overall survival, was better tolerable, and achieved excellent control of brain metastases (6). However, despite good brain penetration, leptomeningeal metastatic disease is still a challenge to osimertinib. Here, the present trial design could serve as an example to study the cerebral pharmacokinetics of next-generation EGFR-TKIs such as osimertinib.

Overall, the results of this well-designed and well-conducted study will help to optimize the treatment regimens in EGFR mutationpositive NSCLC patients with central nervous system metastases.

\section{REFERENCES}

1. Bauer M, Karch R, Wulkersdorfer B, et al. A proof-of-concept study to inhibit ABCG2- and ABCB1-mediated efflux transport at the human blood-brain barrier. J Nucl Med. 2019;60:486-491.

2. Verheijen RB, Yaqub M, Sawicki E, et al. Molecular imaging of ABCB1 and $\mathrm{ABCG} 2$ inhibition at the human blood-brain barrier using elacridar and ${ }^{11} \mathrm{C}$ erlotinib PET. J Nucl Med. 2018;59:973-979.

3. Bahce I, Yaqub MM, Errami H, et al. Effects of erlotinib therapy on $\left[{ }^{11} \mathrm{C}\right]$ erlotinib uptake in EGFR mutated, advanced NSCLC. EJNMMI Res. 2016;6:10.

4. Yaqub M, Bahce I, Voorhoeve C, et al. Quantitative and simplified analysis of ${ }^{11}$ C-erlotinib studies. J Nucl Med. 2016;57:861-866.

5. Kuiper JL, Hendriks L, van der Wekken A, et al. Treatment and survival of patients with EGFR-mutated non-small cell lung cancer and leptomeningeal metastasis: A retrospective cohort analysis. Lung Cancer. 2015;89:255-261.

6. Soria JC, Ohe Y, Vansteenkiste J, et al. Osimertinib in untreated EGFR-mutated advanced non-small-cell lung cancer. $N$ Engl J Med. 2018;378:113-125.

\section{Eveline A. van de Stadt* Maqsood Yaqub Idris Bahce N.H. Hendrikse *Amsterdam UMC, VUmc De Boelelaan 1117} Amsterdam, Netherlands $1081 \mathrm{HV}$ E-mail: e.vandestadt@amsterdamumc.nl

Published online Oct. 4, 2019

DOI: 10.2967/jnumed.119.235705 